\title{
Haematological Profile of Patients with Various Types of Malaria
}

\section{IJCRR}

Section: Healthcare

Sci. Journal Impact

Factor: 6.1 (2018)

ICV: 90.90 (2018)

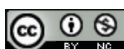

Copyright@IJCRR

\section{Rajneesh Berdia ${ }^{1}$, Naresh Gurbani ${ }^{2}$, Prince Lokwani ${ }^{3}$}

'Associate Professor, Department of Pathology, People's College of Medical Sciences and Research Centre, Bhanpur, Bhopal, MP, India; ${ }^{2}$ Professor, Department of Pathology, People's College of Medical Sciences and Research Centre, Bhanpur, Bhopal, MP, India; ${ }^{3}$ Assistant Professor, Department of Pathology, People's College of Medical Sciences and Research Centre, Bhanpur, Bhopal, MP, India.

\section{ABSTRACT}

Background: Malaria is a disease that is known to be a life-threatening infectious disease and is associated with calamitous complications in many cases and can have drastic and far-reaching consequences in a population. It is one of the parasitic infectious diseases that may affect haematological parameters. Most common haematological complications associated with malaria are Anemia, leukocytosis, thrombocytopenia and leucopenia. The magnitudes of these changes vary with endemic malaria, background hemoglobinopathy, nutritional status, demographic factors and immunity from malaria.

Aim: The main objective of this study is to evaluate the haematological profile of patients infected with malaria.

Material and methods: Total 120 malarial positive patients with the cases of haematological disorders were included in this study. From the patient's Blood samples referred for peripheral blood, the smear was collected in ethylenediaminetetraacetic acid (EDTA) and were also analyzed for malarial parasites with conventional microscopy. Giemsa stain was used for Peripheral smear and also PCV, Hb and WBCs Total counts, RBC morphology, and WBCs differential count and platelet counts are also done.

Result: In this study, the main clinical feature was chill fever. Anaemia was seen in almost all cases of malaria. Leucopenia was seen in $29.17 \%$ of cases. The incidence of leucopenia was $29.4 \%$ in $P$. vivax and in $P$. falciparum was $27.6 \%$ and $33.3 \%$ in both $P$. vivax and falciparum. Monocytosis was seen in $48.24 \%$ cases of $P$. vivax and $17.24 \%$ cases of $P$. falciparum and $33.33 \%$ of incidence in both $P$. vivax and falciparum. The significant co-relation between thrombocytopenia and Malaria was found in this study.

Conclusion: This study showed that almost all blood components and is a true haematological infectious disease and in $P$. falciparum substantially higher compared with $P$. vivax.

Key Words: Malaria, P. falciparum, P. vivax, Thrombocytopenia

\section{INTRODUCTION}

Malaria is a disease which is considered as life-threatening infectious disease and in several cases, it is associated with calamitous complications and can inflict drastic and farreaching consequences within a community. ${ }^{1}$ About 250 million cases in a year were estimated and between one to two million deaths. ${ }^{2}$ This disease is caused by parasitic infection of genus Plasmodium, which gets injected into the human bloodstream through the bite of a female Anopheles mosquito $^{3}$. There are four species of Plasmodium have been known to cause infections in humans such as $P$. falciparum, $P$. vivax, P. ovale, and P. malariae. However, P. knowlesi as another species was known to causes infection in macaque monkeys and reported to cause malaria in humans. ${ }^{4}{ }^{5}$ World Health Organization (WHO) showed about $40 \%$ of the world's people are at risk of malaria. About 300 - 500 million cases of incidence with malaria per year and two million deaths per annum globally have been reported by studies. ${ }^{6}$ The magnitude of these changes varies with endemic malaria, background hemoglobinopathy, nutritional status, demographic factors and immunity from malaria ${ }^{7,89}$ Parasitic infection such as malaria changes in haematological parameters likely to be influenced including endemic diseases that can affect the health of people with various clinical manifestations. Especially in the tropical areas of the world Malaria is a major

\section{Corresponding Author:}

Dr. Naresh Gurbani, Professor, Department of Pathology, People's College of Medical Sciences and Research Centre, Bhanpur, Bhopal, MP, India.

ISSN: 2231-2196 (Print)

Received: 15.05 .2020
ISSN: 0975-5241 (Online)

Revised: 05.07.2020
Accepted: 15.07 .2020 
cause of deaths. In 2010 about 219 million cases were reported worldwide. ${ }^{10}$ Patients with malaria have to have significantly lower platelets; WBCs, eosinophils, lymphocytes; $\mathrm{RBCs}$ and $\mathrm{Hb}$ level whereas neutrophil and monocyte counts were significantly higher in comparison to non-malaria infected patients. ${ }^{11,12}$ Thrombocytopenia is the most common complication during malaria. People having platelet counts $<150,000 / \mu \mathrm{L}$ were $12-15$ times more likely to have malaria than people with platelet counts $>150,000 / \mu \mathrm{L} .{ }^{13}$ Over recent years Malaria infection has been increasing due to a combination of factors including malarial parasites increasing resistance to chemotherapy, Anopheles mosquito vector increasing resistance to insecticides, changes in ecologic and climate and international travel increased to malaria-endemic areas. ${ }^{14}$ For the diagnosis of malaria, peripheral blood smear is considered as Gold standard to show blood smear with the parasite. However in malaria, there is a correlation between $\mathrm{Hb}, \mathrm{WBC}$ counts, platelet count and morphology of RBC. Therefore haematological changes indicate that clinician must develop an efficient and early therapeutic intervention to prevent significant complications from occurring ${ }^{15}$. The main objective of this study is to evaluate the haematological profile of patients infected with malaria.

\section{MATERIAL AND METHODS}

This study was conducted in the Department of Pathology People's College of Medical Sciences and Research Centre, Bhanpur, Bhopal. Total of 120 malarial positive patients with the cases of haematological disorders was included in this study. In this study, patients were convinced for the involvement of sampling method through screening patients admitted from the clinical departments. Detail history of patients was taken as a form of recorded data from the patient's parents or caretaker. From the patient's Blood samples referred for peripheral blood, the smear was drawn through venipuncture by professional staff and $3 \mathrm{ml}$ blood were collected in ethylenediaminetetraacetic acid (EDTA) and were also analyzed for malarial parasites with conventional microscopy. From the sample, the smear was reported as positive when ring forms, schizonts or the sexual forms of any of the species of malaria was seen in the peripheral blood smear. According to their characteristics, morphologic features on microscopy they are further classified. Giemsa stain was used for peripheral smear and also Haemoglobin $(\mathrm{Hb})$ and Total counts of white blood cells, red blood cells morphology and differential count of WBCs and platelet counts are also carried out.

\section{RESULT}

In this study total, 120 malarial positive patients were included in which 75 were males and 45 were females with the ratio $5: 3$. The mean age of patients was $27 \pm 16.45$ years. In this study, male predominance was found. Out of total 120 positive cases, $85(70.83 \%)$ were positive for $P$. vivax, $29(24.17 \%)$ for $P$. falciparum and 6(5\%) had mixed parasitemia, including both $P$. vivax and $P$. falciparum malarial parasites. However, the male to female ratio did not vary significantly across different malarial species. The table no 1 below showed the anaemic cases according to the gender as below $10 \mathrm{~g} / \mathrm{dl}$ or above $10 \mathrm{~g} / \mathrm{dl}$.

\begin{tabular}{|c|c|c|}
\hline Gender & Below 10g/dl & Above 10g/dl \\
\hline Male & 18 & 57 \\
\hline Female & 11 & 34 \\
\hline
\end{tabular}

Table 2: Showing mean Hb Value with species.

\begin{tabular}{lcc} 
Species & Numbers & Mean Hb Value \\
P. vivax & 85 & 11.61 \\
P. falciparum & 29 & 11.36 \\
Both $P$. vivax and falciparum & 6 & 11.14 \\
\hline
\end{tabular}

The above table showed Mean Hb was $11.61 \mathrm{~g} / \mathrm{dl}$ for $P$. vivax and $11.36 \mathrm{~g} / \mathrm{dl}$ for $P$. falciparum and $11.14 \mathrm{~g} / \mathrm{dl}$ for both $P$. vivax and falciparum cases. This was an insignificant finding in this study.

\begin{tabular}{|c|c|c|}
\hline Species & Numbers & $\begin{array}{l}\text { Mean (WBCs/ } \\
\text { cumm) }\end{array}$ \\
\hline P. vivax & 85 & 5289 \\
\hline P. falciparum & 29 & 4890 \\
\hline Both $P$. vivax and falciparum & 6 & 4798 \\
\hline
\end{tabular}

In the above table showed Mean WBC counts was 5289cells/ cumm for $P$. vivax and 4890 cells/cumm for $P$. falciparum and 4798 cells/cumm for both $P$. vivax and falciparum.

\begin{tabular}{lcc} 
Table 4: Cases of Leukopenia according to species. \\
Species & Numbers & Percentage \\
P. vivax & 25 & 29.4 \\
P. falciparum & 8 & 27.6 \\
Both P. vivax and falciparum & 2 & 33.3 \\
\hline
\end{tabular}

The above table showed as Leucopenia was observed in malarial cases. In which $P$. vivax was $29.4 \%$ and in $P$. falciparum was $27.6 \%$ and $33.3 \%$ in both P. vivax and falciparum. 
Table 5: Cases of monocytosis according to species.

\begin{tabular}{lccc} 
Species & $\begin{array}{c}\text { Within normal } \\
\text { range }\end{array}$ & $\begin{array}{c}\text { Above normal } \\
\text { range }\end{array}$ & Total \\
P. vivax & 44 & 41 & 85 \\
P. falciparum & 24 & 5 & 29 \\
$\begin{array}{l}\text { Both P. vivax and } \\
\text { falciparum }\end{array}$ & 4 & 2 & 6 \\
Total & 72 & 48 & 120 \\
\hline
\end{tabular}

The above table showed monocytosis observed in malarial cases. The incidence in P. vivax and P. falciparum cases was $48.24 \%$ and $17.24 \%$ respectively and $33.33 \%$ of incidence in both $P$. vivax and falciparum.

Table 6: Cases showing thrombocytopenia according to species.

\begin{tabular}{lccc} 
Species & Thrombocytopenia & Normal & Percent \\
P. vivax & 62 & 23 & 72.9 \\
P. falciparum & 25 & 4 & 86.2 \\
$\begin{array}{l}\text { Both P. vivax and } \\
\text { falciparum }\end{array}$ & 5 & 1 & 83.3 \\
\hline
\end{tabular}

The above table showed Thrombocytopenia was a significant finding to $76.67 \%$ cases. P. vivax and P. falciparum cases showed Thrombocytopenia as $72.9 \%$ and $86.2 \%$ respectively and $83.3 \%$ showed Thrombocytopenia for both P. vivax and falciparum.

Table 7: Showing Mean value of platelets with species

\begin{tabular}{lcc} 
Species & Numbers & Mean (plts/cu mm) \\
P. vivax & 85 & 77233 \\
P. falciparum & 29 & 70828 \\
$\begin{array}{l}\text { Both } P \text {. vivax and falci- } \\
\text { parum }\end{array}$ & 6 & 70716 \\
\hline
\end{tabular}

The above table showed mean value of the platelets counts with the species of malaria. P. vivax and P. falciparum showed as $77233 \mathrm{plts} / \mathrm{cu} \mathrm{mm}$ and $70828 \mathrm{plts} / \mathrm{cu} \mathrm{mm}$ respectively and 70716 plts/cu mm were shown by both P. vivax and falciparum.

\section{DISCUSSION}

Malaria poses an immense challenge for primary health provider that affects blood indices in various ways with thrombocytopenia and anaemia. Hence major investment and all aspects of malaria need to be taken seriously. Many studies have shown that thrombocytopenia as a sensitive marker for a malaria diagnosis having a sensitivity of $60 \%$, a specificity of $88 \%$ and a positive and negative predictive value of $86 \%$ and $100 \%$, respectively. ${ }^{16},{ }^{17}$ In this study out of total 120 positive cases, $85(70.83 \%)$ were positive for P. vivax, 29 $(24.17 \%)$ for P. falciparum and 6(5\%) had mixed parasitemia, including both $P$. vivax and $P$. falciparum malarial parasites which were concordance with the findings of Erhart et al. ${ }^{18}$ and Jadhav UM et al. ${ }^{19}$. Studies of Rasheed et al. ${ }^{20}$ and Abro et al. ${ }^{21}$ showed that falciparum was the most common species in their studies which was similar to this study.

In this study Hemoglobin $(\mathrm{Hb})$ was $11.61 \mathrm{~g} / \mathrm{dl}$ for P. vivax and $11.36 \mathrm{~g} / \mathrm{dl}$ for P. falciparum and $11.14 \mathrm{~g} / \mathrm{dl}$ for both $P$. vivax and falciparum cases, because of the awareness in patients who had a fever with chills, and came to a diagnostic laboratory for malaria that was detected early and reduced malaria complications. Similarities were also found in the study of Menendez $\mathrm{C}$ et al. ${ }^{22}$. and Sitalakshmi $\mathrm{S}$ et al. ${ }^{23}$. In this studied Mean WBC counts were not significant this was also shown by the other studies of Erhart et al. ${ }^{24}$ and Taha et al. ${ }^{25}$

Leucopenia was observed $29.17 \%$ in malarial cases and that represent the hypersplenism condition which was similar to the studies of Kassa et al. ${ }^{26}$ and Rasheed et al. ${ }^{27}$

In this study monocytosis observed in $40 \%$ of malarial cases which was opposite to the study of Aktar et al. ${ }^{28}$ as it shows $18.9 \%$ cases of cases which represent high reticuloendothelial activity.

In this studied thrombocytopenia was a significant finding to $76.67 \%$ cases of malaria. This may be due to enhanced splenic uptake, the triggers mediated by DIC and immune systems.

This finding was also comparable with other studies conducted by Okocha et $\mathrm{al}^{29}$ and Jhadav et al..$^{30}$ Thrombocytopenia consists of the common characteristic of acute malaria and occurs in both P. falciparum and P. vivax, irrespective of the severe infection. During a case of fever, the lack of regular volume of platelets on a peripheral blood smear is also a sign for malaria diagnosis.

\section{CONCLUSION}

In the malarial disease, almost all blood components and is a true haematological infectious disease. Therefore higher malarial parasitic index was associated with lower platelet counts. In the cases of $P$. falciparum haematological parameters are more affected compared to $P$. vivax. Hence $P$. falciparum has more morbidity than $P$. vivax and if left untreated will lead to severe complications.

Acknowledgement: Authors acknowledge the immense help received from the scholars whose articles are cited and included in references of this manuscript. The authors are 
also grateful to authors / editors / publishers of all those articles, journals and books from where the literature for this article has been reviewed and discussed.

Ethical clearance- Taken from the institutional ethics committee.

\section{Source of funding- Self.}

Conflict of Interest - nil.

\section{REFERENCES}

1. Shaikh QH, Ahmad SM, Abbasi A, et al.: Thrombocytopenia in malaria. J Coll Physicians Surg Pak. 2009, 19:708-10.

2. Sturchler. How much malaria is there worldwide? Parasitol Today $1989 ; 5: 39$.

3. Schlagenhauf-Lawlor P: Travelers Malaria. BC Decker, Inc, Ontario; 2007.

4. Collins WE: Plasmodium knowlesi: a malaria parasite of monkeys and humans. Annu Rev Entomol. 2012, 57:107-21. 10.1146/annurev-ento-121510-133540

5. Chin W, Contacos PG, Coatney GR, Kimball HR: A naturally acquired quotidian-type malaria in man transferable to monkeys. Science. 1965, 149:865.

6. Ullah I, Ali MU, Ali S, Rafiq A, Sattar Z, Hussain S. Hematological Profile of Patients Having Malaria-positive Peripheral Blood Smears: A Cross-sectional Study at a Diagnostic Research Center in Khyber Pakhtunkhwa, Pakistan. Cureus. 2018; 10(9).

7. Erhabor O, Mohammad $\mathrm{H}$ et al. "Effect of plasmodium parasitaemia on some haematological parameters in children living in Sokoto, North Western, Nigeria," International Journal of Clinical Medicine Research, 2014; 1(2) 57-64.

8. Casals-Pascual C, Kai O et al. "Short report: thrombocytopenia in falciparum malaria is associated with high concentrations of IL-10," American Journal of Tropical Medicine and Hygiene, 75(3) 434-436.

9. Cox D \& McConkey S, "The role of platelets in the pathogenesis of cerebral malaria," Cellular and Molecular Life Sciences, 2010; 67(4): 557-568.

10. WHO: World malaria report 2012. Geneva: World Health Organization; 2012.

11. Erhart LM, Yingyuen K, Chuanak N, Buathong N, Laoboonchai A, Miller RS, Meshnick SR, Gasser RA Jr, Wongsrichanalai C: Hematologic and clinical indices of malaria in a semi-immune population of western Thailand. Am J Trop Med Hyg 2004; 70:8-14.

12. Adedapo AD, Falade CO, Kotila RT, Ademowo GO: Age as a risk factor for thrombocytopenia and anaemia in children treated for acute uncomplicated falciparum malaria. J Vector Borne Dis 2007, 44:266-271.
13. Shiraz Jamal Khan YA, Mumtaz Ali M: Thrombocytopenia as an Indicator of Malaria in Adult Population. Malar Res Treat 2012, 405981:1-4.

14. Worrall E, Basu S, Hanson K. Is malaria a disease of poverty? a review of the literature. Trop Med Int Health. 2005; 10(10):1047-1059.

15. Ahmed S, Zakaria F, Aravind P. Variation of haematological indices in various types of malaria. Journal of Evolution of Medical and Dental Sciences. 2014; 26;3(21):5916-25.

16. Lathia TB, Joshi R: Can hematological parameters discriminate malaria from nonmalarious acute febrile illness in the tropics? Indian J Med Sci. 2004, 58:239-44.

17. Patel U, Gandhi G, Friedman S, Niranjan S: Thrombocytopenia in malaria. J Natl Med Assoc. 2004, 96:1212-14.

18. Erhart LM, Yingyuen K, Chuanak N, Buathong N, Laoboonchai A, Miller RS et al. Hematologic and clinical indices of malaria in a semi-immune population of Western Thailand. Am J Trop Med Hyg. 2004; 70(1):8-14.

19. Jadhav UM, Patkar VS, Kadam NN. Thrombocytopenia in malaria - correlation with type and severity of malaria. J Assoc Physicians, India. 2004; 52:615-618.

20. Rasheed A, Saeed S, Khan SA. Clinical and laboratory findings in acute malaria caused by various plasmodium species. J Pak Med Assoc. 2009; 59(4):220-223.

21. Abro AH, Saleh AA, Abdou AS, Ustadi AM, Shuri HMH, Seliem RM. Thrombocytopenia in adults with acute malaria. RMJ. 2009; 34(2):170-172.

22. Menendez C, Fleming AF, Alonso PL. Malaria-related anaemia. Parasitol Today. 2000; 16(11):469-476.

23. Sitalakshmi S, Srikrishna A, Devi S, Damodar P, Mathew T, Varghese J. Changing trends in malaria-a decade's experience at a referral hospital. Indian J Pathol Microbiol. 2003; 46(3):399401.

24. Erhart LM et al. Hematologic and clinical indices of malaria in a semi-immune population of western Thailand. Am J Trop Med Hyg. 2004; 70:8-14

25. Taha et al. Hematological Changes in Malaria: Relation to Plasmodium Species. Kuwait Medical Journal 2007, 39 (3): 262267.

26. Kassa et al. Parasito-haematological features of acute Plasmodium falciparum and P. vivax malaria patients with and without HIV co-infection at Wonji Sugar Estate, Ethiopia. Ethiop J Health Dev. 2005; 19(2):132-139.

27. Rasheed et al. Clinical and laboratory findings in acute malaria caused by various plasmodium species. JPMA. 59:220; 2009.

28. Aktar et al. Hematological changes in malaria: A comparative study. IOSRJPBS. 2012;2(4):15-19.

29. Okocha et al. The prevalence of malaria parasitaemia in blood donors in a Nigerian teaching hospital. J Vect Borne Dis. 2005; 5: $21-24$.

30. Jhadav et al. Thrombocytopenia in Malaria - Correlation with Type and Severity of Malaria. JAPI . 2004; 52: 615-618. 